\title{
Ditching the lifeboat approach to medical ethics
}

\author{
Thieves of Virtue: When Bioethics \\ Stole Medicine \\ Tom Koch \\ MIT Press; 2012
}

A $s$ a recent medical school graduate, I have vivid memories of the confusion and distress many of us felt after medical ethics lectures. Our professors taught autonomy as the prime virtue. But if a patient's competence was impaired or resources became short, professors instructed us to apply utilitarian principles, to the point of ignoring patient autonomy altogether. This seemed arbitrary and subjective. In the face of these contradictions, how could we hope to make ethical decisions in difficult clinical settings?

Tom Koch describes the development of many such paradoxes in bioethics. He methodically reveals the field's foundations and shows how these led to difficulties like the ones we often identify in our medical ethics classes.

Koch begins by imagining a typical student trying to understand a lecture on ethics and objecting to reading philosophy from "a lot of dead Germans."

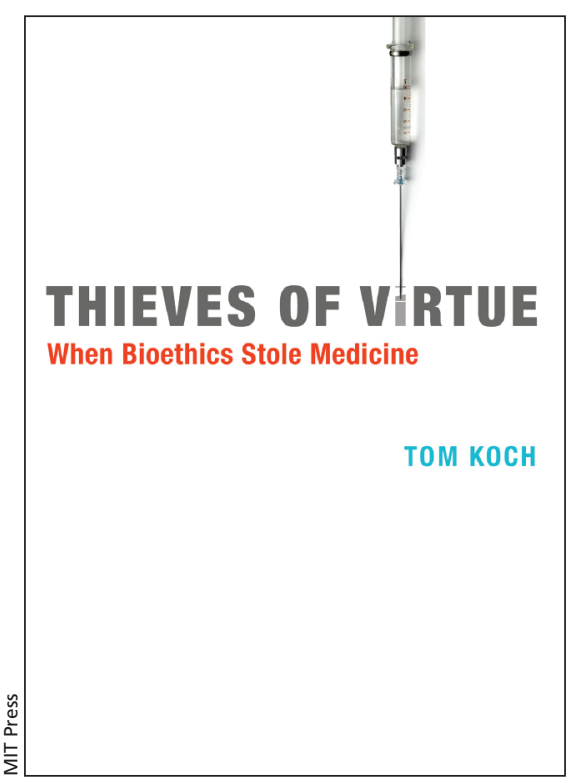

modern ethic is that of a lifeboat. In other words, when resources are limited and there are conflicting imperatives, you must decide who goes in the lifeboat and who does not. In this climate, the tool bioethicists bring to the table is that of philosophy, including the works of John Stuart Mill and Immanuel Kant.

The need for a new medical ethic, according to Koch, however, is not due

\section{Koch questions the entire foundation of biomedical ethics and its use in society.}

Thieves of Virtue is written for the sake of that student, outlining the historical and philosophical underpinnings of modern bioethics piece by piece, story by story.

The leading medical ethics textbook, Principles of Biomedical Ethics, begins with the assertion that in the 20th century, developments in the biological and health sciences have rendered the traditional Hippocratic medical ethic "inadequate for contemporary biomedical ethics." The central metaphor of this to the failure of traditional medical ethics, but rather the neoliberal push for a utilitarian ethic. The important question for bioethics, he argues, is not what to do when you get into a lifeboat situation because of scarce resources, but what social constructs led to these situations in the first place? Why were there not enough lifeboats for all the passengers on the ship? Why was the ship travelling so fast in iceberginfested waters?
Koch argues that we often struggle with resolving problems we have ourselves created. Although we need immediate answers in the clinical realm, the deeper questions of how to avoid such situations in the first place also require attention.

The importance of medical research also plays a prominent role in the story Koch tells. The atrocities condemned at the Nuremberg trials were not solely a German phenomenon but have deep roots throughout the Western world. In Germany, as Koch sees it, the philosophy was taken to its logical endpoint: experimentation on the disabled or imprisoned, a morally repugnant consequence. As a result, the world attempted to establish safeguards to prevent further such abuse. But the philosophical foundation for these actions remains unchallenged, Koch says, arguing that similar dangers still exist for the vulnerable.

Although Thieves of Virtue asks important questions, it is bound to generate controversy. Essentially, Koch questions the entire foundation of biomedical ethics and its use in society. In other words, bioethicists may be out of a job. Koch's storytelling is engaging, peppered by biographies of the major players on the bioethical scene, and interesting accounts of lawsuits and clinical cases. The book creates a comprehensive picture of the current state of bioethics in medicine and in medical research.

\section{Myra Butler MD}

Master's of health sciences candidate

University of British Columbia

Vancouver, BC

\section{Reference}

1. Beauchamp C. Principles of biomedical ethics. New York (NY): Oxford University Press; 2001.

CMAJ 2013. DOI:10.1503/cmaj.130762 